\title{
PENERAPAN LESSON STUDY PADA MATA KULIAH PRAKTIKUM MIKRO KONSELING REALITA
}

\author{
Maghfirotul Lathifah, S.Pd., M.Pd \\ Program Studi Bimbingan dan Konseling \\ Universitas PGRI Adi Buana Surabaya \\ maghfirotul@unipasby.ac.id \\ maghfibk07@gmail.com
}

\begin{abstract}
Lesson study is a structured process adapted from Japan that enables to plan, observe, analyze, and define actual classroom lesson. This study aims to enable students to practice counseling with reality approach. The research used qualitative descriptive method with the following stages. (a) plan; (b) do; (c) see. The results showed that the achievement of learning practicum micro counseling reality by applying lesson study reached $80 \%$. The findings of this study are expected to explore and open educators that will learn from a lesson.

Lesson study adalah proses terstruktur dari Jepang yang memungkinkan untuk merencanakan, mengamati, menganalisa, dan mendefinisikan fakta pembelajaran di kelas. Penelitian ini bertujuan agar mahasiswa mampu mempraktikan konseling dengan pendekatan realita. Penelitian menggunakan metode deskriptif kualitatif dengan tahapan sebagai berikut. (a) perencanaan atau plan; (b) pelaksanaan atau do; (c) refleksi atau see. Hasil penelitian menunjukkan bahwa ketercapaian pembelajaran praktikum mikro konseling realita dengan menrapkan lesson study tercapai sebesar $80 \%$. Temuan penelitian ini diharapkan dapat mengeksplorasi dan membuka pendidik bahwa pendidik akan belajar dari suatu pembelajaran.
\end{abstract}

Kata kunci: Lesson study, Praktikum mikro konseling, Realita

\section{PENDAHULUAN}

Lesson study merupakan istilah dari Jugyokenkyu. Jugyo berarti pelajaran dan Kenkyu bermakna sebagai studi atau penelitian. Lesson study adalah model pengembangan profesional yang banyak digunakan oleh guru di
Jepang, dimana mereka melakukan penelitian sistematis terhadap praktik pedagogis yang telah dilaksanakan melalui observasi (Fernandez, 2002; Saito \& Atencio, 2013). Dalam praktik pembelajaran, setiap kelompok terdiri dari tiga sampai lima guru profesional, secara kolaboratif 
mengobservasi

"proses

pembelajaran" yang dirancang untuk

proses peningkatan prestasi siswa.

Secara profesional mereka

mengobservasi area konten

pembalajaran dan menetapkan

capaian tujuan pembelajaran

(Puchner \& Taylor, 2006; Saito \&

Atencio, 2013)

Lesson study merupakan bentuk pengembangan profesional jangka panjang dimana tim dosen akan menyusun, melakukan penelitian, dan mempelajari instruksi pelajaran sebagai cara untuk menentukan bagaimana mahasiswa belajar dengan sebaik-baiknya. Hal ini menandakan adanya proses yang memperdalam interaksi komunitas belajar profesional, dengan mengembangkan kebiasaan refleksi diri dan berfikir kritis melalui kolabrasi dengan rekan kerja serta pengamatan terstruktur terhadap mahasiswa. Lesson study memiliki kekuatan untuk mengubah kehidupan kampus (Armstrong, 2011).

Proses pembelajaran lesson study bertepatan dengan gagasan bahwa belajar adalah proses sosial sekaligus proses bagi guru kelas untuk memanfaatkan kelasnya, karena kelas mereka merupakan tempat terbaik untuk belajar dan memperbaiki praktik mengajar yang telah diimplementasikan. Observasi dan FGD pasca pembelajaran didasarkan pada gagasan bahwa suatu pelajaran memiliki banyak aspek baik konten ataupun pedagogi yang harus diberikan dengan penuh pertimbangan untuk memperbaiki pembelajaran (Sims \& Walsh, 2009). Hal ini merupakan kesempatan dimana para guru mendiskusikan tantangan yang mereka hadapi selama proses pembelajaran berlangsung yang bermuara pada pengembangn teknik pengajaran baru (Cochran Smith \& Lytle, 2001; Saito \& Atencio, 2013). Penting untuk dicatat bahwa dalam keseluruhan proses lesson study, penekanannya adalah pada pembelajaran siswa dan mengumpulkan bukti interaksi kelas yang sebenarnya. Lesson study bukan berfokus pada perilaku guru (Puchner \& Taylor, 2006). Kegiatan terakhir dari lesson study ialah refleksi yang harus dipertimbangkan pada implementasi pembelajaran berikutnya. 
Proses pembelajaran pada perkuliahan program studi bimbingan dan konseling tidak terlepas dari kegiatan praktikum untuk mengasah ketajaman para calon konselor dalam mengimplementasikan teori (dalam hal ini pendekatan konseling). Mata kuliah praktikum mikro konseling menuntut para calon konselor untuk mengimplementasikan berbagai pendekatan yang sudah dipelajari dalam teori dan teknik konseling. Para calon konselor dituntut untuk tidak hanya mampu secara teori, namun juga mampu mempraktikkan strategi dalam pendekatan tersebut tanpa mengesampingkan keterampilan dasar konseling. Hal ini sesuai dengan standar kompentensi konselor dalam kompetensi sosial yang tertuang pada Permen 27 Tahun 2011.

Pada kegiatan praktikum, mahasiswa seringkali takut dan enggan untuk belajar. Hal tersebut nampak ketika proses kegiatan kelompok secara bergantian. Mahasiswa enggan untuk menjadi konselor. "Bu nanti gantian kan bu jadi konselornya, $\mathrm{Bu}$, kugh saya sich bu yang jadi konselor, saya jadi konseli aja ya bu". Kalimat tersebut sering bermunculan ketika praktikum mikro konseling. Berdasarkan permasalah tersebut, maka perlu dilakukan perbaikan konsep pembelajaran pada mata kuliah praktikum mikro konseling. Alternatif yang dapat digunakan dalam memperbaiki konsep pembelajaran pada mata kuliah praktikum mikro konseling ialah dengan menggunakan kegiatan lesson study.

\section{METODE}

Penelitian ini menggunakan metode deskriptif kualitatif untuk menggambarkan fenomena atau kejadian yang terjadi saat penelitian berlangsung, antara lain: (a) Apakah semua mahasiswa benar-benar telah belajar topik pembelajaran hari ini; (b) Siapa mahasiswa yang tidak mengikuti kegiatan pembelajaran dengan baik; (c) Mengapa mahasiswa tersebut tidak dapat belajar dengan baik; (d) Usaha apa yang dilakukan dosen untuk mendorong mahasiswa yang tidak aktif dalam proses pembelajaran; (e) Apakah mahasiswa tertarik dengan media yang 
digunakan dalam pembelajaran; (f) Bagaimana mahasiswa bekerja sama dalam memecahkan masalah atau menyelesaikan tugas yang diberikan dosen; (g) Bagaimana ketercapaian tujuan dari pembelajaran yang telah dilakukan; (h) Pelajaran berharga apa yang dapat dipetik dari pengamatan pembelajaran hari?

Penelitian ini dilaksanakan di Universitas PGRI Adi Buana Surabaya. Subjek atau sumber data penelitian dalam kegiatan penerapan lesson study pada mata kuliah praktikum mikro konseling realita ialah 15 mahasiswa angkatan 2015 kelas A2 dan dosen model. Tahapan yang dilaksanakan dalam penelitian ini ialah (a) plan atau perencanaan; (b) do atau pelaksanaan dan (c) see atau refleksi. Uraian tahapan lesson study sebagai berikut.

a. Plan atau perencanaan

Pada tahapan plan, dosen model membahas pelaksanaan open class, kemudian menyusun perangkat perkuliahan (RPS dan SAP) dan menyiapkan hand out, lembar kegiatan atau observasi mahasiwa, menyiapkan prosedur monitoring, dan membentuk kelompok kecil yang terdiri dari 3-4 mahasiswa. Tahapan perencanaan diawali dengan analisis kebutuhan dan permasalahan yang dihadapi dalam perkuliahan, persiapan membelajarkan mahasiswa, mensiasati kekurangan sarana dan prasana, sehingga dapat mengetahui kondisi riil perkuliahan.

b. Do atau pelaksanaan

Pada tahapan do, dosen model melaksanakan proses perkuliahan sesuai dengan rencana (plan). Tim dosen yang membantu melaksanakan observasi secara langsung terhadap aktivitas belajar mahasiswa.

c. See atau refleksi

Pada tahapan see, dosen model memberikan refleksi selama proses perkuliahan berlangsung. Kegiatan pada tahapan ini dipimpin langsung oleh moderator yang merangkap sebagai observer. Observer lainnya sejumlah 4 dosen dengan Prof. Hera sebagai pendamping. Tahapan see atau refleksi 
diarahkan pada analisis data, capaian tujuan pembelajaran dan bagaimana perkembangan mahasiwa, serta feed back atau umpan balik terhadap rancangan perkuliahan.

Proses selanjutnya ialah dosen model melaksanakan perkuliahan sesuai dengan RPS (rancangan perkuliahan semester) dan SAP yang telah disusun pada tahap perencanaan atau plan.

\section{HASIL DAN PEMBAHASAN}

\section{Open Class Pertama}

Open class pertama dilaksanakan hari selasa, dengan setting kelas satu observer mengamati 3 sampai 4 mahasiswa. Di awal perkuliahan dosen model menginformasikan tujuan pembelajaran yang akan dicapai dan membagikan hand out beserta lembar observasi perkuliahan praktikum mikro konseling realita. Selama proses perkuliahan (do) rekan sejawat melaksanakan observasi. Dosen model mereview kembali pengetahuan tentang konseling realita yang telah dipelajari pada semester sebelumnya, antara lain: (a) siapakah tokoh dari pendekatan konseling realita; (b) kebutuhan dasar dalam konseling realita; (c) prinsip $3 \mathrm{R}$; (d) pribadi sehat; (e) prosedur konseling realita; (f) teknik konseling dalam pendekatan relita.

Proses selanjutnya ialah mahasiswa diminta untuk praktik konseling realita secara berkelompok dengan pengetahuan dasar yang sudah di dapat pada semester sebelumnya. Satu kelompok terdiri dari 3 mahasiswa, dengan pembagian konselor, konseli, dan observer. Pada proses konseling secara berkelompok, dosen model mengamati setiap kelompok dan menemukan satu kelompok yang lupa prosedur konseling realita serta tidak bisa melanjutkan proses konseling sampai selesai. Setelah proses praktikum dengan kelompok kecil selesai, dosen model menunjuk mahasiwa secara acak untuk praktik di depan. Mahasiswa yang lain mengamati jalannya proses konseling yang diaksanakan dan mengisi lembar observasi. Dosen model merekam proses konseling dengan menggunakan HP. Setelah proses konseling selesai, dosen model memberikan feed back atau umpan 
balik dari proses konseling dan memberikan tugas rumah, yakni analisis kasus dengan harapan mahasiswa mampu mereview kembali apa yang sudah di dapat hari ini dan kemarin.

Memasuki proses terakhir yakni refleksi (see), dimana proses ini dilaksanakan ketika perkuliahan berakhir. Moderator sekaligus observer membuka proses FGD dan mempersilahkan dosen model menyampaikan persepsinya selama proses perkuliahan, dilanjutkan dengan observer memberikan ulasan, refleksi perkuliahan yang telah dilaksanakan dosen model, serta penguatan. Hasil dari FGD, yakni sebagai berikut. (a) Font yang dibuat oleh dosen model dalam perkuliahan terlalu kecil; (b) Pada proses kelompok mahasiswa yang tidak aktif ialah mahasiswa yang menjadi observer; (c) Dosen model perlu memberikan tagihan agar mahasiswa mau belajar dan membaca materi; (d) Shock terapi yang menurut dosen model agar mahasiswa kembali berkonsentrasi, perlu diterapkan dengan cara lain, misalnya jurnal belajar atau buku harian; (e) ketercapaian perkulliahan sebesar $70 \%$. Pelajaran berharga yang dipetik oleh observer selama proses open class pertama ialah dosen model kecil-kecil cabe rawit dimana dosen model sudah menanggapi pertanyaan mahasiswa dengan lantang dan jelas, serta usaha dosen model untuk mendorong mahasiswa agar aktif, tak lupa keruntutan dalam mereview materi secara mendalam.

\section{Open Class Kedua}

Open class kedua ini dilaksanakan untuk memperbaiki kekurangan yang terjadi pada open class pertama. Kegiatan pertama yang dilakukan oleh dosen model ialah mereview perkuliahan, memutar video proses konseling realita dan menjelaskan strategi atau teknik konseling realita beserta contoh. Namun ketika proses pemutaran video terjadi masalah dimana suara terlalu kecil dan akhirnya dosen model meminta untuk demostrasi di depan kelas. Pada saat dosen model menunjuk mahasiswa untuk demosntrasi di depan, mahasiswa tersebut mengatakan " $\mathrm{Bu}$, kugh saya sich bu yang jadi konselor, saya jadi 
konseli aja ya bu, itu ajalah bu". Setelah proses demosntrasi selesai selanjutnya dosen model mereview hasil demosntrasi dan memberikan penguat

\section{Refleksi pada open class} kedua ialah sebagai berikut. (a) tujuan pembelajaran sudah tercapai $80 \%$; (b) dosen model mampu berimprovisasi ketika melakukan perkuliahan; (c) terdapat mahasiswa yang tidak on pada menit pertama, namun di menit selanjutnya sudah on; (d) mahasiswa tertarik dengan media yang digunakan, namun perlu memberikan animasi dalam power point yang ditampilkan; (e) ulasan materi perkuliahan diberikan secara runtun; (f) dosen model perlu meningkatkan kemampuan berbahasa inggris. Pelajaran berharga yang dipetik oleh observer selama proses open class kedua ialah keruntutan dosen model dalam memberikan materi serta perhatian yang intens dalam pendampingan praktikum mikro konseling realita

\section{KESIMPULAN DAN SARAN}

Penerapan lesson study pada mata kuliah praktikum mikro konseling didasarkan pada proses riil, bukan karena diamati namun lebih kepada usaha yang berkesinambungan. Dosen dituntut untuk merubah cara penyampaian yang biasanya digunakan pada perkuliahan secara klasikal dirubah menjadi lebih eksploratif dan berinovasi, agar meningkatkan kualitas proses perkuliahan serta pemahaman mahasiswa akan materi yang disampaikan, sehingga mampu untuk mempraktikan konseling realia. Secara garis besar dosen akan belajar dari suatu pembelajaran. Lesson study mengajarkan bahwa ruang kelas perkuliahan merupakan lingkungan kerja paling kompleks dimana seorang profesional harus berada dan beroperasi. Lesson study membuka mata dosen dari apa yang terjadi. Artinya, lesson study membantu dosen untuk (a) melihat lebih tajam dan rinci apa yang sebenarnya terjadi pada mahasiswanya; (b) melihat kesenjangan antara apa yang diduga dengan apa yang sebenarnya terjadi ketika mahasiswa belajar; (c) mencari tahu bagaimana merencanakan pembelajaran yang lebih baik sesuai 
dengan kebutuhan mahasiswa; (d) mengubah cara pengajaran atau perkuliahan yang lebih baik.

\section{REFERENSI}

Armstrong, A. (2011). Lesson study puts a collaborative lens on student lerning. Summer, 2-7.

Cochran Smith, M. \& Lytle, S. (2001). Beyond certainty:taking an inquiry stance on practice. In. A. Lieberman \& M. Lynne (Eds.), Teachers caught in the action: professional development that matters. New York: Teachers College Press.
Sim, L. \& Walsh, D. (2009). Lesson study with preservice teacher: lesson from lessons. Teaching and Teacher Education, 25 (5), 724-733.

Saito, E. \& Atencio, M. (2013). A conceptual discussion of lesson study from a micro political perspective: implication for teacher development and pupil learning. Teacher and Teacher Education, 31, 87-95.

Puchner, L.D. \& Taylor, A. R. (2006). Lesson study, collaboration and teacher efficacy: stories from two school based math lesson study groups. Teaching and teacher education, 22 (7), 922-934. 